\title{
Efficacy of Aerosol Applications of Methoprene and Synergized Pyrethrin Against Tribolium castaneum Adults and Eggs
}

\author{
ANGELA M. TUCKER, ${ }^{1}$ JAMES F. CAMPBELL, ${ }^{2}$ FRANK H. ARTHUR,${ }^{2,3}$ AND KUN YAN ZHU ${ }^{1}$
}

\begin{abstract}
J. Econ. Entomol. 107(3): 1284-1291 (2014); DOI: http://dx.doi.org/10.1603/EC13507
ABSTRACT Experiments were performed to determine the efficacy of a single aerosol application of the insecticides methoprene and piperonyl butoxide-synergized pyrethrin, alone or in combination, and the insecticide carrier, Isopar M, against Tribolium castaneum (Herbst), the red flour beetle. The initial test exposed adults to insecticide treatments and placed male/female pairs in flour. All adults exposed to synergized pyrethrin were knocked down for at least $24 \mathrm{~h}$ after exposure but they recovered. High adult survival and similar average numbers of living $\mathrm{Fl}$ progeny were produced regardless of treatment exposure. In a separate test, insecticide treatments were directly applied to newly laid eggs, which resulted in the suppression of egg hatch. Synergized pyrethrin was the most effective insecticide $(P \leq 0.001)$ for suppressing egg hatch. The effect of flour on insecticide activity to eggs and consequent insect development was also evaluated. An amount of $0.01 \mathrm{~g}$ of flour in the exposure arena, $62-\mathrm{cm}^{2}$ area, was not sufficient for individuals to develop beyond the early larval stages, regardless of the treatment. As the flour amount in the arena increased from 1 to $5 \mathrm{~g}$, the number of eggs that could develop to the adult stage increased, but this number was significantly lower in the insecticide treatments than in the control or carrier treatments. The results of the later tests indicate a high efficacy of the insecticides alone or in combination on $T$. castaneum egg hatch and development to the adult stage.
\end{abstract}

KEY WORDS Tribolium castaneum, methoprene, synergized pyrethrin, efficacy, aerosol application

Tribolium castaneum (Herbst), the red flour beetle, is a cosmopolitan stored product insect pest that can be found in warehouses, pet food stores, and grain processing facilities such as rice and flour mills. It is considered a major insect pest species and is frequently one of the least susceptible stored product beetle pest species to insecticides (Arthur 2008). Integrated pest management programs that incorporate tactics such as aerosol insecticide applications and sanitation measures are used by the milling and processing industries in the United States, but data regarding the efficacy of these strategies are limited.

Aerosol applications involve dispersal of an insecticide as small droplets under pressure using either a permanently installed system or a portable applicator (Peckman and Arthur 2006). Insecticides applied as an aerosol can provide good coverage of exposed surfaces, but they cannot penetrate into commodities or obstructed areas (Peckman and Arthur 2006; Arthur 2008). Piperonyl butoxide-synergized pyrethrin combined with the insect growth regulator methoprene is a commonly used insecticide aerosol mixture. This insecticide combination has been found to effectively reduce the number of $T$. castaneum individuals cap-

\footnotetext{
${ }^{1}$ Department of Entomology, Kansas State University, 123 West Waters Hall, Manhattan, KS 66506.

${ }^{2}$ United States Department of Agriculture, Agricultural Research Service, Center for Grain and Animal Health Research, 1515 College Ave., Manhattan, KS 66502

${ }^{3}$ Corresponding author, e-mail: frank.arthur@ars.usda.gov.
}

tured in traps when used with other pest management tactics, including methyl bromide fumigation and sanitation (Campbell et al. 2010a,b).

The combination of methoprene and synergized pyrethrin is used as an aerosol because each insecticide has a different mode of action. Methoprene affects immature development by delaying development, causing deformities (Henrick 2007), reducing survival to the adult stage (Loschiavo 1974, Williams and Amos 1974, Arthur, 2001, Arthur and Hoernemann 2004), and causing reduced fertility in the surviving adults (Loschiavo 1974, Oberlander et al. 1997, Chanbang et al. 2007, Wijayaratne et al. 2012), but it does not kill adults. Synergized pyrethrin will provide control of adults, but mortality may be affected by several factors, including aerosol distribution and the presence of a food source (Arthur and Campbell 2008). The efficacy of synergized pyrethrin has been evaluated for T. castaneum adults (Arthur 2008) and eggs (Toews et al. 2010), and the efficacy of methoprene has been evaluated for late-stage T. castaneum larvae (Arthur 2008).

These studies provide evidence for the efficacy of the individual components of the combination methoprene and synergized pyrethrin on their target developmental stages but do not evaluate the combination. In addition, aerosols are usually formulated in a solvent or carrier for dispersal. The carrier, Isopar M, is a solvent produced by distilling petroleum and is frequently used as a carrier for synergized pyrethrin. In a recent study, this solvent reduced the adult emer- 
gence of eggs of Plodia interpunctella (Hübner), the Indian meal moth, exposed to the carrier (Jenson et al. 2010). There are no published data in scientific journals regarding the effect of this carrier on $T$. castaneum developmental stages.

Therefore, the first objective of this study was to evaluate the efficacy of synergized pyrethrin alone and in combination with methoprene along with the carrier, Isopar $\mathbf{M}$, on $T$. castaneum adults directly exposed to the aerosol and on the resulting progeny production of those exposed adults. The second objective was to evaluate the aerosol efficacy against the egg stage. This objective had two sub-objectives. The first sub-objective evaluated the insecticide effect on egg hatch. The second sub-objective evaluated the effect of different levels of flour accumulation on the insect development after direct aerosol exposure to the egg stage.

\section{Materials and Methods}

A colony of T. castaneum originally collected in 2004 at a commercial flour mill in Kansas (Romero et al. 2010) was used in the experiments described later. Insect cultures were initiated by adding 100 adults to $280 \mathrm{~g}$ of unbleached wheat flour with $5 \%$ (by weight) brewer's yeast (MP Biomedicals LLC, Solon, $\mathrm{OH}$ ) in a 720-ml glass canning jar (Jarden Home Brands, Daleville, IN). Adults were removed after $3 \mathrm{~d}$ using a size 30, 0.59-mm (mesh sieve opening diameter) brass sieve (W.W. Tyler Co., Mentor, $\mathrm{OH}$ ), and the flour was returned to the canning jar. Jars were held in an incubator (I-36 Series Incubator, Percival Scientific Inc., Perry, IA) maintained at $28.0 \pm 0.0^{\circ} \mathrm{C}, 46 \pm 0.1 \%$ $\mathrm{RH}$, and a photoperiod of 14:10 (L:D) h (Tucker 2012, Tucker et al. 2013a,b). Insect voucher specimens were deposited in the Kansas State University Museum of Entomological and Prairie Arthropod Research (KSUMEPAR) under voucher number 226.

Effects on Adult Survival and Progeny Production. Exposure arenas were created in plastic petri dishes ( 90 by $15 \mathrm{~mm}, 62 \mathrm{~cm}^{2}$ surface area of the bottom of the petri dish) using a concrete patching material (Rockkite, Hartline Products, Co., Inc., Cleveland, OH). The material was mixed with water to create a slurry, which was then poured into the bottom of each petri dish to create a concrete surface (Arthur 2008). Before the aerosol treatment groups of males and females were generated by sexing mixed-age adults. Males were identified by the presence of a setiferous patch on the ventral side of the first femur, but females lack this patch (Hinton 1942). Approximately 20 males and 20 females were placed in separate petri dishes. Petri dishes that did not receive an aerosol application (untreated control) were placed on a table in a different room from where the insecticide applications occurred and the lids were removed. The petri dishes that contained males were placed on the opposite end of the table from the petri dishes that contained females. Water applications were not used because previous studies showed no significant differences in mortality, adult emergence, or external physical deformities between the untreated controls and those that were sprayed with water (Tucker 2012, Tucker et al. 2013a,b).

Two petri dishes, one containing 20 male insects and the other 20 females, that were designated for a simulated aerosol insecticide application were placed in a larger plastic box. The larger plastic boxes were prepared by mixing concrete patching material and pouring the mixture into the bottom of the boxes. The plastic boxes had interior dimensions of $56.5 \pm 0.2 \mathrm{~cm}$ (length) by $34.6 \pm 0.3 \mathrm{~cm}$ (width) by $15.5 \pm 0.1 \mathrm{~cm}$ (height) after the layer of concrete was added to the bottom. A separate box was used for each aerosol treatment.

The insecticides used in the test were as follows. The synergized pyrethrin was a $1 \%$ active ingredient ([AI]) formulation (Entech Fog-10, Entech Systems, Kenner, LA) that was preformulated in an oil carrier (Isopar M, Exxon Mobile, Houston, TX) and applied at the rate of $30 \mathrm{ml} / 28 \mathrm{~m}^{3}$. A separate source of Isopar M was also obtained from Entech Systems to be used either alone or mixed with methoprene. The formulation of methoprene was Diacon II (33.6\% [AI], 288 $\mathrm{mg}[\mathrm{AI}] / \mathrm{ml}$, Central Life Sciences, Schaumberg, IL). The label application rate is $3 \mathrm{ml}$ of the formulation mixed with either water or an oil-based carrier applied to a volume of $280 \mathrm{~m}^{3}$. Therefore, the combination of synergized pyrethrin and methoprene is applied in a 1:100 ratio. In an actual field application, an aerosol is applied from a dispensing system, and the insecticide residues would settle to the flooring surface. During such an application, some of the insecticides in the aerosol would be lost, so we postulated a $25 \%$ loss rate. We then used the dimensions of a floor of a commercial mill (118.0 m [length] by $190.2 \mathrm{~m}$ [width] by $30.5 \mathrm{~m}$ [height]) to calculate an application rate for the surface of the box. The floor of this mill had a volume of $684 \mathrm{~m}^{3}$ with a floor area of $224 \mathrm{~m}^{2}$. The amount of synergized pyrethrin formulation needed to treat the volume of this room would be $725 \mathrm{ml}$, assuming a 75\% deposition rate gives $544 \mathrm{ml}$ for a flooring surface area of $224 \mathrm{~m}^{2}$. The dose applied to a given surface area of floor during an aerosol application will not be constant in all applications because it will be impacted by the shape of the room and the various features inside the room (shelving, pipes, pallets, equipment, for example). Therefore, we needed to select a given room as a model to calculate the dosage and selected a mill room of the following dimensions and estimated what percentage would adhere to other surfaces or be lost during aeration. We consulted with pest management professionals who regularly apply aerosols inside flour mills, and they advised us to postulate this $25 \%$ loss rate. Hence, converting from this area of $224 \mathrm{~m}^{2}$ for the model room to the surface area of $1,944 \mathrm{~cm}^{2}$ of the plastic box yields an application rate of $0.5 \mathrm{ml}$ per box.

Based on the aforementioned calculations, $0.5 \mathrm{ml}$ of synergized pyrethrin formulation (which contains the carrier, Isopar M) was evenly dispensed on the flooring surface of each box containing the petri dishes with adult beetles using an artist's air-brush (E Badger Air Brush 100 LGM, Badger Air-Brush Company, Franklin Park, IL) to apply the insecticides. Because the metho- 
prene is applied in a 1:100 ratio, $0.5 \mathrm{ml}$ of methoprene was mixed with $50 \mathrm{ml}$ of synergized pyrethrin formulation, and then $0.5 \mathrm{ml}$ of this mixture was evenly applied to the boxes treated with the combination of methoprene and synergized pyrethrin. Similarly, to apply methoprene only with the carrier, $0.5 \mathrm{ml}$ of methoprene was mixed with $50 \mathrm{ml}$ of Isopar $\mathrm{M}$ and then $0.5 \mathrm{ml}$ of this mixture was applied. Finally, to treat the boxes with Isopar $\mathrm{M}$ alone, $0.5 \mathrm{ml}$ of just the carrier was applied to the box flooring surface.

A 1-h ventilation period followed the aerosol applications. Immediately after the ventilation period and every day for $15 \mathrm{~d}$, the adults were classified as active, knocked down (on their backs and unable to right themselves), or dead (no response to stimulation). Following the ventilation period, one male and one female from the same treatment were placed in new 90 - by $15-\mathrm{mm}$ (62$\mathrm{cm}^{2}$ ) petri dishes with $5.02 \pm 0.01 \mathrm{~g}$ of the same flour, as used for insect rearing. Ten dishes with male/female pairs were prepared for each treatment. Fifteen days after the aerosol application, the adults were removed from the flour by sieving with a size- 30 mesh sieve and a final mortality determination was made at that time.

The flour was held for an additional $30 \mathrm{~d}$ to enable progeny to develop to the adult stage. After the $30 \mathrm{~d}$, the flour was sieved with a size-30-mesh brass sieve to remove larvae, pupae, and adults, and a size-60 sieve (0.25-mm mesh sieve; W.S. Tyler Co., Mentor, $\mathrm{OH}$ ) to remove eggs. The total number of progeny (eggs, larvae, pupae, and adults) was counted. Adults were classified as alive with no physical morphological malformations, dead, or either live or dead that were malformed in some manner (i.e., external abnormalities such as twisted wings and previous molts and pupal exuvia attached to cuticle).

This experiment was repeated three different times, blocks, using different sets of treated individuals, resulting in 30 replicates per treatment. Adult mortality data were analyzed using the GLIMMIX Procedure of the Statistical Analysis System (SAS software version 9.2, SAS Institute, Cary, NC), which is a generalized linear model (GLM), using binary (alive: yes/no) data. The progeny data, total number of living individuals regardless of developmental stage, were analyzed using the GLM Procedure and the TukeyKramer least means separation test (SAS Software).

Effect on Egg Hatch. Concrete petri dishes were prepared as previously described. Five (1 by $1-\mathrm{cm}$ ) pieces of double-sided sticky tape (J. V. Converting Inc. Co., Fairless Hills, PA) were placed in the center of the petri dish. The pieces of tape were arranged with one in the middle (center) of the petri dish and two directly above and two directly below the center piece. None of the pieces of tape were touching each other.

To obtain eggs for the experiment, three groups of 100 adult $T$. castaneum were removed from established laboratory colony jars. Each group of adults were placed in a 473-ml glass canning jar (Jarden Home Brands, Daleville, IN) with $250 \mathrm{~g}$ of flour, previously sieved through a size-60 mesh sieve. Twenty-four hours later, eggs from one jar were removed from the flour using a size-60 mesh sieve. The collected eggs were placed in a glass petri dish. An aspirator was used to collect T. castaneum eggs in groups of 10 , which were placed on top of each piece of tape in the concrete petri dishes for 50 eggs per petri dish. The tape prevented the eggs from moving around in the petri dish during handling.

The five treatments, Isopar $\mathbf{M}$; methoprene and Isopar M; synergized pyrethrin and Isopar M; methoprene, synergized pyrethrin, and Isopar M; or no aerosol applications (untreated control), were applied to the concrete petri dishes containing eggs using the procedures described earlier. After treatment, the petri dishes containing eggs were observed daily for $1 \mathrm{wk}$ to determine the percentage of eggs that hatched. Because neonate larvae tend to eat their egg shells after they have hatched, successful egg hatch was defined as the number of neonate larvae observed in the petri dish that had fully escaped from the egg. Preliminary research showed that neonate larvae were able to crawl across the adhesive tape without becoming stuck. This experiment was repeated twice with three replicate petri dishes per block, resulting in six replicates in total for each treatment. The number of eggs hatched was determined for each day and analyzed using Proc GLIMMIX with repeated measures and a Tukey-Kramer least means separation test (SAS software). The model included the day of hatch, block (day of treatment), treatment, replicate (dish), and number of eggs hatched. The first $3 \mathrm{~d}$ were not included in the model because there were no eggs hatched in any of the treatments during that period.

Effect of Flour Amount on Egg Hatch and Development. Concrete petri dishes were made as described earlier for the egg hatch experiment, but only one ( 1 by $1-\mathrm{cm})$ piece of double-sided sticky tape was placed in the center of the dish. Eggs used in the experiment were collected as described earlier. Ten eggs were added to each petri dish before the petri dish was treated in the larger plastic box. The treatments and insecticide application protocol were the same as described earlier.

To simulate different levels of sanitation that can occur in a facility and that could impact the amount of insecticide to which an egg is exposed, $0.01 \mathrm{~g}, 1 \mathrm{~g}$, or $5 \mathrm{~g}$ of flour was placed on the surface of the concrete petri dishes after the aerosol application. The three levels of flour were intended to represent different sanitation levels: a good level of sanitation (a flour dusting, $0.01 \mathrm{~g}$ ), a poor level of sanitation (flour completely covers the surface and eggs, $5 \mathrm{~g}$ ), and an intermediate sanitation level (partially covers the surface and eggs, $1 \mathrm{~g}$ ).

Ten dishes were prepared for each treatment combination and sanitation level. The experiment was repeated twice for 20 replicates. The petri dishes were held for 5 weeks at $27^{\circ} \mathrm{C}, 60 \% \mathrm{RH}$, and a photoperiod of 16:8 (L:D) h in a growth chamber (model CTH-811, Percival Scientific Inc., Perry, IA), and then the number of living developmental stages (larvae, pupae, and/or adults) present was determined. Data were analyzed using the GLM procedure and the TukeyKramer least means separation test (SAS software). 


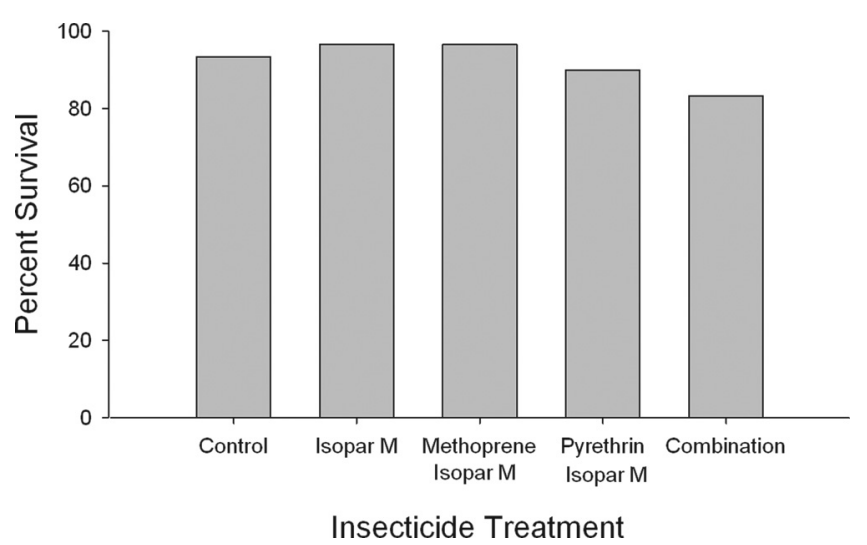

Fig. 1. The mean percentage (the SEM is too small to be seen on the graph) of adults that were alive a week after exposure to aerosol applications of Isopar M; methoprene and Isopar M; synergized pyrethrin and Isopar M; methoprene, synergized pyrethrin, and Isopar M (combination); or unexposed (control). There were no significant differences in mortality means based on Tukey-Kramer least square means for multiple comparisons $(P \geq 0.05)$.

\section{Results}

Effects on Adult Survival and Progeny Production. All T. castaneum adults exposed to treatments containing synergized pyrethrin (synergized pyrethrin and Isopar M; methoprene, synergized pyrethrin, and Isopar M) were knocked down for $24 \mathrm{~h}$ after treatment, but no knockdown was observed in the treatments that did not contain synergized pyrethrin. Beetles that were knocked down recovered so that after $2 \mathrm{wk}$, there were no significant differences in mortality between treatments (Fig. $1 ; F=0.20$; df $=4,287 ; P=$ 0.9358 ). The interactions for gender and between gender and treatment were also not significantly different $(F=0.01 ; \mathrm{df}=1,287 ; P=0.9894$ and $F=0.20 ; \mathrm{df}=$ 4,$287 ; P=0.9358$, respectively).

The mean total number of living $\mathrm{F} 1$ progeny (combined adults, pupae, and larvae) in petri dishes $5 \mathrm{wk}$ after aerosol application on adults was not significantly different $(F=0.63 ; \mathrm{df}=4,143 ; P=0.6441)$ among the treatments (control 47.6 \pm 5.3; Isopar M $35.3 \pm 6.8$; methoprene and Isopar M 48.2 \pm 5.9 ; synergized pyrethrin and Isopar M $40.2 \pm 6.5$; and methoprene, synergized pyrethrin, and Isopar M $34.1 \pm 6.3$ ). However, the percentage of progeny with external physical morphological deformities was significantly different among the treatments $(F=3.60$; $\mathrm{df}=4,143 ; P=$ $0.0079)$. The Isopar $\mathrm{M}$ treatment had fewer deformities $(10.8 \pm 2.2 \%)$ than either of the two treatments that contained methoprene (methoprene and Isopar M [23.8 $\pm 2.9 \%]$ and methoprene, synergized pyrethrin, and Isopar M [23.8 $\pm 3.9 \%])$. The remaining two treatments, control $(15.6 \pm 2.5 \%)$ and synergized pyrethrin and Isopar M $(20.0 \pm 3.1 \%)$, were not significantly different from each other or any of the other treatments.

Effect on Egg Hatch. Differences in percentage of egg hatch among the treatments were observed $(F=$ 94.22; df $=4$, 412; $P<0.0001 ;$ Fig. 2$)$. Significantly more eggs hatched in the untreated control and in the Isopar M treatments than when eggs were exposed to methoprene or synergized pyrethrin (formulated in Isopar M), either alone or in combination. The interactions for day of hatch $(F=125.80 ; \mathrm{df}=2,412 ; P<0.0001)$, between treatment and day of hatch $(F=24.71 ; \mathrm{df}=8,412 ; P<$ 0.0001 ) and between block (day) and day of hatch $(F=$ $12.02 ; \mathrm{df}=2,412 ; P<0.0001)$, were also significant. However, the interactions between block and treatment $(F=1.66 ; \mathrm{df}=4,412 ; P=0.1592)$ and between block, treatment, and day of hatch $(F=1.82 ; \mathrm{df}=8,412 ; P=$ 0.0711) were not significant.

Effect of Flour Amount on Egg Hatch and Development. The mean number of adults that were observed 5 wk after treating eggs was significantly different among the different combinations of insecticide and flour level (sanitation) treatments $(F=$ $69.82 ; \mathrm{df}=14,349 ; P<0.0001)$. Insecticide treatment, flour depth, and the interaction between the insecticide treatment and flour depth were all significant $(F=111.93 ; \mathrm{df}=4,359 ; P<0.0001, F=110.01 ; \mathrm{df}=$ 2,$361 ; P<0.0001, F=40.14$; df $=8,355 ; P<0.0001$, respectively). Among the insecticide treatments, the mean number of adults in the controls was significantly greater than the Isopar $\mathbf{M}$ treatment, which in turn was significantly greater than the other insecticide treatments (Fig. 3). The mean number of adults in the methoprene and Isopar M, synergized pyrethrin and Isopar M, and combination of methoprene, synergized pyrethrin, and Isopar M was essentially zero and significantly lower than number of adults in eggs exposed to Isopar $\mathbf{M}$ or untreated controls.

The mean number of adults was significantly different among the levels of flour (Tukey-Kramer test, $P<0.05$ ), with no adults observed in the 0.01-g (Fig. 3A) flour level treatment, higher numbers observed in the 1-g (Fig. 3B) flour level treatment, and the highest numbers in the 5-g (Fig. 3C) flour level treatment. The significant interaction between insecticide treatment and flour depth is likely owing to the fact that the 0.01and 1-g flour depth levels are insufficient for insect development, so the efficacy of the different insecticides cannot be determined, but at the 5 -g flour depth 


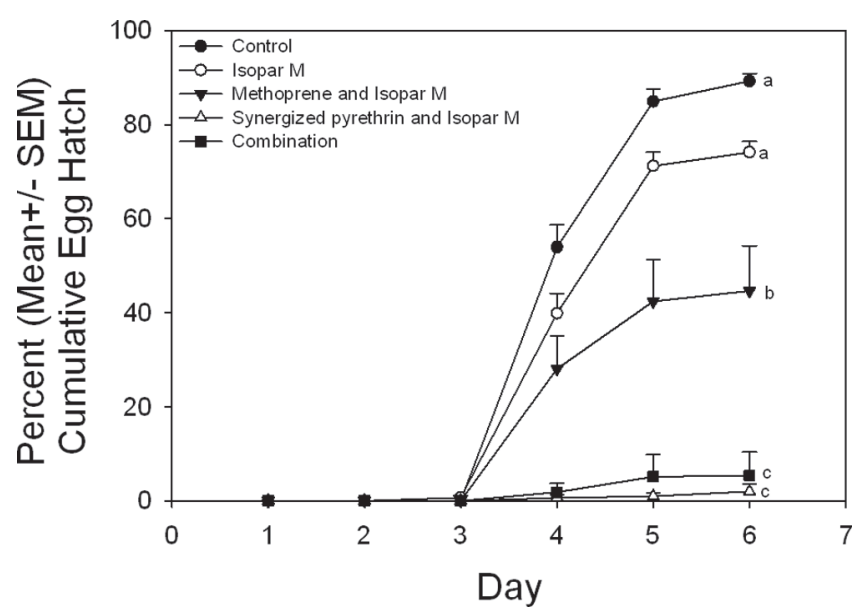

Fig. 2. The percentage (mean \pm SEM) cumulative egg hatch of 24-h T. castaneum eggs that received an aerosol application of Isopar M; methoprene and Isopar M; synergized pyrethrin and Isopar M; methoprene, synergized pyrethrin, and Isopar M (combination); or no aerosol applications (control). Same lowercase letters next to the treatment on Day 6 indicate no significant differences in means according to Tukey-Kramer least square means comparison test $(P \geq 0.05)$.

level, normal insect development occurred and the efficacy of the insecticides can be determined.

The full GLM model for the average number of immatures observed $5 \mathrm{wk}$ after direct exposure of the eggs to the insecticide and flour depth treatment combinations showed significant differences $(F=27.22$; $\mathrm{df}=14$, $349 ; P<0.0001$ ). The mean number of immatures observed was significantly different among insecticide treatment $(F=48.86 ; \mathrm{df}=4,359 ; P<0.0001$; Fig. 3$)$ and flour depth $(F=50.22 ; \mathrm{df}=2,361 ; P<0.0001)$, with a significant interaction between treatment and sanitation $(F=12.64 ; \mathrm{df}=8,355 ; P<0.0001)$.

Eggs that were exposed to methoprene, synergized pyrethrin, and Isopar $\mathrm{M}$ had significantly greater number of individuals develop to the larval and/or pupal stages than those that were exposed to all other treatment combinations. Eggs exposed to synergized pyrethrin and Isopar M had the lowest number of individuals developing to the larval and/or pupal stages. However, this was not significantly different from eggs that were exposed to Isopar M; methoprene, synergized pyrethrin, and Isopar M; or untreated (controls). The mean number of immatures in eggs that were covered with $0.01 \mathrm{~g}$ (Fig. 3A) and 5 g (Fig. 3C) of flour was significantly lower than eggs that were covered in $1 \mathrm{~g}$ (Fig. 3B) of flour. This is likely owing to the inability of insects to develop normally in the 0.01 amount of flour; normal development in the noninsecticide treatments, control and Isopar $\mathrm{M}$, in 1 and $5 \mathrm{~g}$ of flour; and very few individuals developing to adulthood in the $5 \mathrm{~g}$ of flour.

\section{Discussion}

Arthur and Campbell (2008) noted recovery of adult Tribolium confusum Jacqueline DuVal, the confused flour beetle, after exposure to synergized pyrethrin. The rate of recovery of $T$. castaneum adults exposed to synergized pyrethrin in Isopar $\mathbf{M}$ or in combination with methoprene is higher than previ- ously reported (Arthur 2008). Arthur (2008) had reported a high rate of mortality of adult $T$. castaneum regardless of the presence of a flour patch, food source, during an aerosol application of synergized pyrethrin. Differences between the current study and the previous one could result from susceptibility differences between the two colony strains. This study uses insects that were collected from a commercial mill in 2008 (Romero et al. 2010), but the previous study (Arthur 2008) used adult beetles from a laboratory colony that had been maintained since before 1958. These two colonies could have different susceptibilities owing to time of collection, differences in insecticide exposure, and length of time under laboratory selection pressures and conditions. In addition, Rigaux et al. (2001) found that strains of T. castaneum from 14 different global locations had between 5 and $50 \%$ mortality after exposure to diatomaceous earth. Similarly, Sehgal et al. $(2013,2014)$ reported variation in susceptibility of field strains of stored product insects exposed to contact insecticides. The differing results between laboratory and field studies could also relate to the level of variation in aerosol distribution in field sites, i.e., there could be areas inside the field sites that might have more aerosol deposition compared with the more controlled laboratory conditions.

There were no significant differences in the total number of living F1 progeny regardless of treatment. This suggests that adult fitness was not reduced and that insecticide(s) were not vertically or horizontally transferred by contact with the treated T. castaneum parental adults or the flour that should have contained amounts of insecticide. However, treatments including methoprene, either with Isopar M or the combination of insecticides, had significantly higher percentage of progeny with external physical malformations, which indicates a possibility that horizontal transfer of methoprene did occur. Previous studies have shown the movement of methoprene from treated individuals 


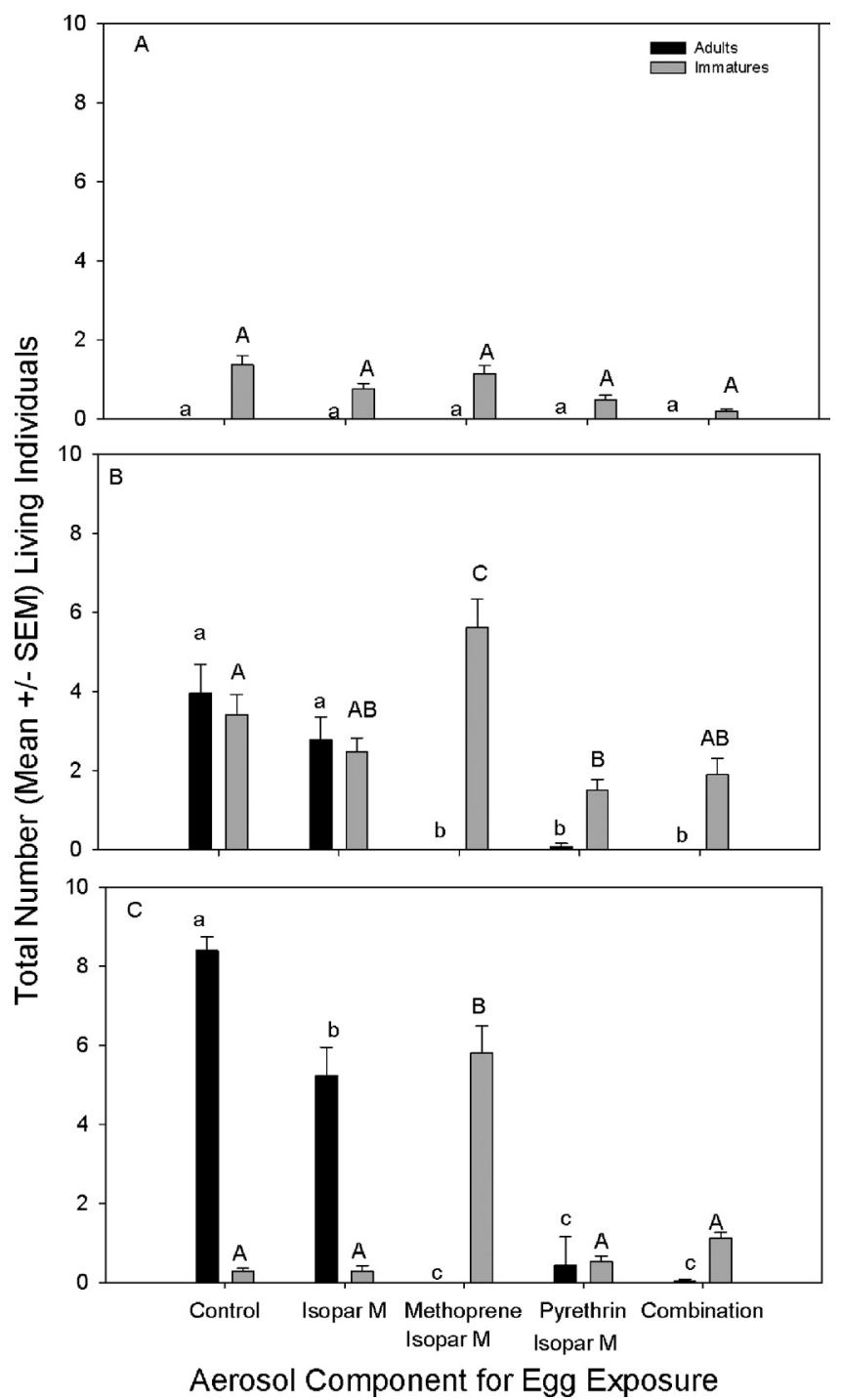

Fig. 3. The number (mean \pm SEM) of T. castaneum adults or immatures present 5 weeks after an aerosol application of Isopar M; methoprene and Isopar M; synergized pyrethrin and Isopar M; methoprene, synergized pyrethrin, and Isopar M (combination); or no aerosol applications (control) and an amount of flour [0.01 g (A), $1 \mathrm{~g}$ (B), or $5 \mathrm{~g}$ (C) ] was added postaerosol application. Same lowercase (adults) or uppercase (immatures) letters above bars indicate no significant differences among insecticide treatment means within a flour depth according to least square means test with a Tukey-Kramer multiple comparisons adjustment $(P \geq 0.05)$.

into flour and the subsequent negative effects on previously untreated individuals exposed to this flour (Tucker 2012, Tucker et al. 2014a,b). The failure to see an effect of the synergized pyrethrin might be either because this insecticide was not transferred as readily to the flour as was for methoprene or that the $\mathrm{Fl}$ progeny were more susceptible to the low amounts of methoprene transferred into the flour compared with the synergized pyrethrin. The increase in deformities in the progeny of adults treated with methoprene may have greater cumulative effects on populations because it has been previously shown that deformed individuals have reduced fitness (Loschiavo 1974, Williams and Amos
1974, Oberlander et al. 1997, Arthur 2001, Arthur and Hoernemann 2004, Chanbang et al. 2007).

Eggs were shown to be susceptible to treatments with synergized pyrethrin, with individuals treated with either synergized pyrethrin mixed with Isopar M or mixed with methoprene and Isopar $\mathbf{M}$ having the lowest successful hatch rate. Egg hatch was reduced by exposure to methoprene and Isopar M compared with the untreated control but not as much as with synergized pyrethrin. The carrier Isopar $\mathbf{M}$ did not significantly increase egg mortality compared with the untreated controls, so the observed egg hatch reductions were likely due to the insecticide treatments and 
not an effect of the carrier. There was no significant increase in efficacy by combining the methoprene and the synergized pyrethrin, but it is difficult to improve on essentially $0 \%$ egg hatch after exposure to synergized pyrethrin alone. However, in an earlier study with eggs of $P$. interpunctella, the Isopar M carrier did have a slight effect and reduced egg mortality relative to untreated controls (Jenson et al. 2010). Therefore, an additive effect of the kerosene carrier on eggs would not be unusual. In this test control, egg mortality was $<25 \%$, which corresponds to earlier studies where egg mortality ranged from 10\% (Sokoloff 1974) to 25\% (Brijwani et al. 2012). Extending the egg hatch observations out past $6 \mathrm{~d}$ could increase the successful egg hatch, but neonate larvae readily consume their egg shells. In addition, on Day 7 , the neonate larvae were observed cannibalizing the eggs and neonate larvae that had either not hatched or were in the process of hatching.

The treatment representing a high level of sanitation, which corresponded to a low amount of flour $(0.01 \mathrm{~g})$, was not sufficient for the beetles to complete development in the controls. No adults were observed and the surviving larvae were much smaller than in the other flour depth treatments. The same pattern was observed in the insecticide treatments with no increase in mortality, so it appears under these conditions, sanitation is sufficient to provide control and additional insecticide applications do not increase the efficacy. The fact that the eggs were exposed to methoprene and Isopar M, Isopar $\mathbf{M}$ alone, and untreated control all had $>40 \%$ egg hatch at Day 6 supports our hypothesis that the small amount of flour was insufficient for the insects to complete their development with $0.01 \mathrm{~g}$ flour per petri dish. It is also possible that larvae could have hatched but were cannibalized (Park et al. 1965) because preliminary data demonstrated that the larvae at this flour level, $0.01 \mathrm{~g}$, would cannibalize each other. Good sanitation levels (low flour residues) improved the efficacy of synergized pyrethrin and pyrethroid aerosol applications (Toews et al. 2010) and heat treatments (Brijwani et al. 2012). However, our results suggest that in low amounts of flour residues, T. castaneum development is not likely to occur and therefore the effects of insecticide cannot be detected.

The mixture of mostly larvae and pupae along with a small number of adults in the 1-g-flour petri dishes regardless of treatment suggests that development to the adult stage was inhibited owing to insufficient resources. The adults that were present were primarily in the control and Isopar M treatments, which suggests that at this flour depth, there is an insecticide effect as well as a sanitation effect. There were a small number of adults present in the synergized pyrethrin and Isopar M treatment, whereas the two treatments with methoprene had no adults present at this flour depth, which further suggests a delay in development. This observation has been reported previously for $P$. interpunctella eggs and larvae exposed to methoprene (Jenson et al. 2009). This delay in development could potentially result in population effects, which may ultimately suppress insect population growth.
The low numbers of adults in the treatments receiving an insecticide application indicate a high insecticide efficacy on insect development. However, there were a greater number of immature developmental stages in the 1-g and 5-g-flour petri dishes. While these differences were not significantly different, the presence of insects suggests a potential for incurring some economic losses owing to the presence of live insects and cast skins (Baur 1984). However, this was only one spray application and it is likely that with repeated aerosol applications, there would be a greater effect. In addition, the percent of mortality on eggs is higher than previously reported (Toews et al. 2010). This is likely owing to the differences in methods. Toews et al. (2010) applied synergized pyrethrin to eggs that were in different flour depths. The presence of the flour patch covering T. castaneum eggs simulates the scenario where a flour patch that was not removed during routine sanitation or where routine sanitation may not occur. The flour patch can serve as a shelter in which the insect could escape or hide from the insecticide applications. Our study simulated exposure of $T$. castaneum eggs directly exposed to an aerosol application, and during routine milling, different depths of flour fall on top of the eggs, potentially providing a shelter from the insecticides or drawing the insecticide into the flour and away from the treated surfaces. Both scenarios are likely to occur at the same time in commercial flour mills and this adds to the complexity of determining the effects of sanitation and aerosol applications on the resident $T$. castaneum populations.

In conclusion, flour residues that could result from differing levels of sanitation may affect the efficacy of insecticides. When sanitation is good, low flour depths, egg hatch and subsequent development to adulthood are suppressed and the use of insecticides does not increase the efficacy. However, it is difficult to completely remove all flour residues during routine sanitation practices. In addition, as the depth of flour increases more individuals successfully emerged as adults, but at the flour depths tested, the insecticides are effective at suppressing adult emergence. In addition, there may be flour depths where the insecticides will not be effective at suppressing adult emergence because it is more likely that the individuals can readily escape from the insecticides. The components of methoprene and synergized pyrethrin, alone or in combination, appear to have little effect on the mortality of adults or on subsequent F1 progeny when applied as a single aerosol application. However, it is possible that with multiple spray applications, which occur under normal insect pest management scenarios, there are cumulative insecticide effects on individuals, which could result in suppression of beetle populations.

\section{Acknowledgments}

We thank Doug VanGundy of Central Life Sciences for supplying methoprene and Robert Drudge of Entech Systems for supplying the Entech Fog-10 and Isopar M; Casey Persson, Brian Sanborn, Marshal Van Tuyl, Dillon Robbins, 
Konner Cool, Brian Barnett, and Rich Hammel for technical support and advice. We also thank Subramanyam Bhadriraju, Susan Brown, and David Margolies for comments on earlier drafts. Research was partially funded by the U.S. Department of Agriculture, National Institute of Food and Agriculture (NIFA) Methyl Bromide Transitions program (grant number 201051102-21660). This is KAES contribution number 14-160-J. Mention of trade names or commercial products in this publication is solely for the purpose of providing specific information and does not imply recommendation or endorsement by the U.S. Department of Agriculture or Kansas State University. USDA is an equal-opportunity provider and employer.

\section{References Cited}

Arthur, F. H. 2001. Susceptibility of last-instar red flour beetles and confused flour beetles (Coleoptera: Tenebrionidae) to hydroprene. J. Econ. Entomol. 94: 772-779.

Arthur, F. H. 2008. Aerosol distribution and efficacy in a commercial food warehouse. Insect Sci. 15: 133-140.

Arthur, F. H., and C. K. Hoernemann. 2004. Effect of physical and biological factors on susceptibility of Tribolium castaneum and Tribolium confusum (Coleoptera: Tenebrionidae) to new formulations of hydroprene. J. Stored Prod. Res. 40: 251-268.

Arthur, F. H., and J. F. Campbell. 2008. Distribution and efficacy of pyrethrin aerosol to control Tribolium confusum (Coleoptera: Tenebrionidae) in food storage facilities. J. Stored Prod. Res. 44: 58-64.

Baur, F. J. 1984. Introductory background information, pp. 1-14. In F. J. Bauer (ed.), Insect management for food storage and processing. American Association of Cereal Chemists, St. Paul, MN.

Brijwani, M., B. Subramanyam, and P. W. Flinn. 2012. Effect of varying levels of sanitation on mortality of Tribolium castaneum eggs and adults during heat treatment of a pilot flour mill. J. Econ. Entomol. 105: 703-708.

Campbell, J. F., M. D. Toews, F. H. Arthur, and R. T. Arbogast. 2010a. Long term monitoring of Tribolium castaneum populations in two flour mills: rebound after fumigation. J. Econ. Entomol. 103: 1002-1011.

Campbell, J. F., M. D. Toews, F. H. Arthur, and R. T. Arbogast. 2010b. Long term monitoring of Tribolium castaneum populations in two flour mills: seasonal patterns and effect of fumigation. J. Econ. Entomol. 103: 991-1001.

Chanbang, Y., F. H. Arthur, G. E. Wilder, and J. E. Throne. 2007. Efficacy of diatomaceous earth and methoprene, alone and in combination, against Rhyzopertha dominica (F.) (Coleoptera: Bostrychidae). J. Stored Prod. Res. 43: 96-401.

Henrick, C. A. 2007. Methoprene. Am. Mosq. Control Assoc. Bull. 7: 225-239.

Hinton, H. E. 1942. Secondary sexual characters of Tribolium. Nature 149: 500-501.

Jenson, E. A., F. H. Arthur, and J. R. Nechols. 2009. Efficacy of methoprene applied at different temperatures and rates on surface substrates to control eggs and fifth instars of Plodia interpunctella. J. Econ. Entomol. 102: 1992-2002.

Jenson, E. A., F. H. Arthur, and J. R. Nechols. 2010. Efficacy of an esfenvalerate plus methoprene aerosol for the control of eggs and fifth instars of Plodia interpunctella (Lepidoptera: Pyralidae). Insect Sci. 17: 21-28.
Loschiavo, S. R. 1974. Tests of four synthetic insect growth regulators with juvenile hormone activity against seven species of stored products insects. Manit. Entomol. 9: $43-52$.

Oberlander, H., D. L. Silhacek, E. Shaaya, and I. Ishaaya. 1997. Current status and future perspectives of the use of insect growth regulators for the control of stored product insects. J. Stored Prod. Res. 33: 1-6.

Park, T., D. B. Mertz, W. Grodzinski, and T. Prus. 1965. Cannibalistic predation in populations of flour beetles. Physiol. Zool. 38: 289-321.

Peckman, P. S., and F. H. Arthur. 2006. Insecticide space treatments in food plants, pp. 175-182. In J. Heaps (ed.), Insect management for food storage and processing, $2^{\text {nd }}$ ed. AACC, Minneapolis, MS.

Rigaux, M., E. Haubruge, and P. G. Fields. 2001. Mechanisms for tolerance to diatomaceous earth between strains of Tribolium castaneum. Entomol. Exp. Appl. 101: 33-39.

Romero, S. A., J. F. Campbell, J. R. Nechols, and K. A. With. 2010. Movement behavior of red flour beetle: response to habitat cues and patch boundaries. Environ. Entomol. 39: 919-929.

Sehgal, B., B. Subramanyam, F. H. Arthur, and B. S. Gill. 2013. Variation in susceptibility of field strains of three stored grain insect species to spinosad and chlorpyrifosmethyl plus deltamethrin on hard red winter wheat. J. Econ. Entomol. 106: 1911-1919.

Sehgal, B., B. Subramanyam, F. H. Arthur, and B. S. Gill. 2014. Variation in susceptibility of field strains of three stored grain insect species to spinosad and chlorpyrifosmethyl plus deltamethrin on wheat. Pest Manage. Sci. 70: $576-587$.

Sokoloff, A. 1974. The biology of Tribolium, with special emphasis on genetic aspects, vol II. Oxford University Press, Ely House, London, United Kingdom.

Toews, M. D., J. F. Campbell, and F. H. Arthur. 2010. The presence of flour affects the efficacy of aerosolized insecticides used to treat the red flour beetle, Tribolium castaneum. J. Insect Sci. 10: 1-14.

Tucker, A. M. 2012. Horizontal transfer of methoprene and its effect on Tribolium castaneum (Herbst) individuals and populations. Ph.D. dissertation. Kansas State University, Kansas.

Tucker, A. M., J. F. Campbell, F. H. Arthur, and K. Y. Zhu. 2014a. Mechanisms for horizontal transfer of methoprene from treated to untreated Tribolium castaneum (Herbst). J. Stored Prod. Res. 57: 36-42.

Tucker, A. M., J. F. Campbell, F. H. Arthur, and K. Y. Zhu. 2014b. Horizontal transfer of methoprene by Tribolium castaneum (Herbst) and Tribolium confusum Jacquelin du Val. J. Stored Prod. Res. 57: 73-79.

Wijayaratne, L.K.W., P. G. Fields, and F. H. Arthur. 2012. Effect of methoprene on the progeny production of Tribolium castaneum (Coleoptera: Tenebrionidae). Pest Manag. Sci. 68: 217-224.

Williams, P., and T. G. Amos. 1974. Some effects of synthetic juvenile insect hormones and hormone analogues on Tribolium castaneum (Herbst). Aust. J. Zool. 22: 147-153.

Received 22 November 2013; accepted 23 February 2014. 